\title{
Mundos do trabalho em diálogo: a importância das interseções para a História do Trabalho
}

\author{
Worlds of labor in dialogue: the importance of intersections in the Labor \\ History field
}

\section{Alessandra Belo Assis Silva*}

SURIANO, Juan; SCHETTINI, Cristiana (org.). Historias cruzadas: diálogos historiográficos sobre el mundo del trabajo en Argentina y Brasil. Buenos Aires: Teseo, 2019.

Palavras-chave: Mundos do trabalho; diálogos historiográficos; histórias cruzadas. Keywords: Worlds of labor; historiographic dialogue; intersected histories.

A renovação no campo teórico e metodológico da história social do trabalho, desde fins do século XX, já é bastante conhecida. Alguns desses resultados, entretanto, têm-se mostrado cada vez mais refinados e aprofundados. Tais efeitos referem-se tanto à ampliação do que se entende por "mundos do trabalho" quanto ao alargamento da própria noção de "trabalho".

No primeiro movimento, diversas dimensões das vidas de homens e mulheres trabalhadores foram incorporadas dentro do amplo universo no qual estão inseridos. Nesse caminho, destaca-se o tratamento dado a importantes marcadores sociais, como etnicidade, raça, nacionalidade, gênero, além dos temas culturais como sociabilidade e lazer para citar os mais debatidos. Esses elementos, empregados de forma interseccional, passaram a ser vistos como fatores cruciais para o entendimento dos processos de formação das classes sociais e dos conflitos de classes. Afinal, como a historiografia tem ressaltado, eles não se configuram como reinos distintos da experiência, que existem em franco isolamento entre si.

Já o segundo impacto dessa transformação, em que a noção de trabalho é revisitada e ampliada, consiste na crítica à visão historiográfica que estabelece poderosas barreiras e diferenciações limitadas em relação ao significado de “trabalho". Um exemplo revela-se na famigerada dicotomia entre escravidão e trabalho livre em que uma se encaminharia de forma progressiva e linear para a outra, tornando as análises indiferentes às diversas modalidades intermediárias

* Doutoranda em História Social, pela Universidade Estadual de Campinas (UNICAMP). Mestra em História pela Universidade Federal de Juiz de Fora (UFJF). E-mail: alessbelo@gmail.com. ORCID: https://orcid. org/0000-0002-5685-4094. 
de trabalho. Em oposição a essa marcha, tornou-se mais interessante para os historiadores alargar o sentido próprio do termo e admitir a concomitância e mesmo a interdependência de diferentes formas de trabalho ao longo da história, bem como reconhecer as incertezas dos limites legais que regulam tais relações.

Ambos os movimentos, embora tenham se configurado como uma renovação fecunda no campo da história social do trabalho, tornaram-se, por outro lado, um desafio complexo em relação à absorção desses avanços nas pesquisas, principalmente, para os historiadores em formação. Recentemente, veio à tona um empreendimento exemplar no sentido de oferecer algumas respostas a essas questões, com base em um frutífero diálogo entre pesquisadores latino-americanos com larga experiência. Trata-se da coletânea Historias cruzadas: diálogos historiográficos sobre el mundo del trabajo en Argentina y Brasil, organizada por Juan Suriano (a quem o livro tem dedicação póstuma) e Cristiana Schettini, que conta com contribuições de ambos e de mais oito autores brasileiros e argentinos, a saber: Mirta Lobato, Fabiane Popinigis, Claudio Batalha, Silvana Palermo, Enrique Mases, Leonardo Affonso de Miranda Pereira, Paulo Fontes e Fernando Teixeira da Silva.

Em um primeiro momento, pode-se ter a impressão de que o volume é um projeto vinculado ao campo cada vez mais crescente da história global e transnacional, cujo intuito é associar experiências histórico-nacionais diversas. Entretanto, como os próprios organizadores informam, os cinco encontros que deram origem ao livro, realizados pela chamada Redhisoc (Rede de História Social e Cultural dos Mundos do Trabalho na Argentina e Brasil), não estão ligados propriamente a uma história transnacional ou a um desejo de fazer uma história comparada entre as duas nações.

O resultado desse diálogo parece ser, diversamente, o de conectar complexos temas de pesquisa sobre os mundos do trabalho tanto da Argentina como do Brasil com o fito de formar novos eixos capazes de organizar e estimular estudos vindouros. A base para esse esforço reside nas afinidades metodológicas entre os historiadores de ambos os países, sob a influência compartilhada dos rigores empíricos de E. P. Thompson. Com efeito, as cinco "chaves temáticas" que dividem o livro revelam a inspiração thompsoniana e a relevante contribuição dos trabalhos para a área da história social do trabalho.

A primeira chave consiste na relação entre gênero, classe e suas conexões com o racismo que formam o eixo de entrada da coletânea, com os trabalhos de Mirta Lobato e Fabiane Popinigis. Desafiando os limites da periodização, Lobato estudou os espaços de trabalho na indústria da carne da Argentina entre os séculos XIX e XX, que de matadouros a frigoríficos, foram caracterizados, de uma maneira geral, pela presença de animais mortos, sangue e odores desagradáveis que favoreceram a construção de uma imagem de degradação ambiental transmitida para a figura que se fazia dos próprios trabalhadores. No entanto, a pesquisadora demonstra como tal fenômeno foi pior para as mulheres, na medida em que elas perderam os atributos associados à feminilidade. Com uma metodologia criativa e rigor acadêmico, a autora utiliza um rico conjunto documental identificado com a literatura ficcional argentina, fotografias e desenhos da época para entrar na interessante dimensão das representações culturais da masculinidade e da feminilidade.

A historiadora Fabiane Popinigis também lança mão dos elementos de raça e gênero para desnaturalizar a ideia, já referida, da existência de categorias de trabalho estanques como a oposição radical entre escravidão e liberdade. 
Ela estuda mulheres africanas e afrodescendentes, escravas e libertas, no século XIX, em Desterro (Florianópolis). Trata-se de mulheres integradas ao comércio, vendedoras "ambulantes, quitandeiras, pombeiras e mascates". Tais atividades, com nomenclaturas diversas, ao contrário do que possa parecer, se utilizarmos apressadamente sentidos próprios do século XX, fazem referência a uma espécie de trabalho formalizado, registrado nos documentos oficiais do período em tela. Como demonstra a autora, essas mulheres "estavam no centro da parte mais produtiva e rentável da economia, algo que a perspectiva centrada no paradigma do trabalho livre, assalariado e masculino como o único capaz de produzir valor, não permitiu perceber".

Outro cruzamento interessante, presente no livro, está na intersecção realizada entre história política e história social do trabalho. As análises hodiernas têm trazido contribuições importantes para a compreensão de como a experiência social e cultural de homens e mulheres trabalhadoras cruzou-se com atividades públicas e oficiais, evidenciando a importante entrada desses sujeitos nos ambientes da política formal, espaço que, por muito tempo, foi colocado como apartado da realidade dos trabalhadores. Esses estudos, em síntese, englobam dois eixos importantes do livro.

No primeiro, há os capítulos de Cláudio Batalha e Silvana Palermo ambientados no início do século XX no Brasil e na Argentina. Estudando o caso brasileiro na Primeira República e fazendo algumas comparações com a Argentina, Batalha demonstra a existência, de um lado, de uma distância entre militância operária e política eleitoral que tem forte ligação com as desconfianças a respeito das fraudes nos pleitos. De outro lado, por meio do estudo das candidaturas de indivíduos ligados à classe trabalhadora, o autor verifica a existência de um espaço para a ação desses sujeitos em defesa de seus próprios interesses (fenômeno que foi mais permeável e competitivo na Argentina que no Brasil). Silvana Palermo, estudando o caso argentino, introduz a importante dimensão cultural traduzida nas celebrações dos trabalhadores em torno da grande greve ferroviária de 1917 no país. A pesquisadora demonstra que, em algumas dessas festividades, os representantes de diferentes partidos políticos adquiriram um papel relevante transformando o ambiente em um verdadeiro ato oficial entre os trabalhadores, os quais a conhecida lei eleitoral Sáenz Peña, aprovada em 1912, havia transformado em cidadãos de pleno direito.

É justamente com o enfoque nos marcadores culturais que Leonardo Pereira e Paulo Fontes realizam seus estudos e completam mais um eixo de interseção entre história política e história do trabalho. Pereira, ao analisar as sociedades carnavalescas no Rio de Janeiro na Primeira República, mostra novamente a importância de se tratar a experiência social das classes subalternas de forma orgânica e articulada. Nessa perspectiva, a identidade coletiva dos trabalhadores é formada tanto pelas suas disputas, que também são políticas, quanto pelos laços criados dentro do ambiente cultural das ruas, na contramão de uma visão que dissociava os mundos do trabalho da oscilante noção de cultura popular. O estudo de Paulo Fontes dirige-se pelo mesmo caminho, agora no ano de 1953, em São Paulo, ao estudar as redes de sociabilidade formadas pelos trabalhadores. Essas malhas eram tecidas por intermédio de relações informais cuja articulação formava a base de uma verdadeira "onda associativa" e de ação política experimentada pelas classes populares em São Paulo naquele período. Fontes demonstra que os sindicatos, definitivamente, não eram os únicos elos de associação da classe operária em um período de forte combatividade do movimento. 
Outra chave importante da compilação reside nas discussões em torno da questão nacional. Se o objetivo dos autores não foi fazer uma história transnacional, ou global, o questionamento dos limites trazidos pelo nacionalismo metodológico, crítica presente também naquelas correntes, é evidente. De fato, a compreensão sobre as fragilidades das fronteiras nacionais é outro ponto chave da coletânea. Não se trata, obviamente, de uma repulsa ao tema da nação. O livro coloca a questão nacional como um importante objeto de pesquisa, em franca e complexa problematização, e não como uma perspectiva teórico-metodológica incontornável a partir da qual se escreve a história.

Não é por acaso que um dos eixos da compilação se refere ao "trabalho nas margens da nação”. Nesse item, há os capítulos de Cristiana Schettini e Enrique Mases. A pesquisadora estuda a prostituição dentro da noção de trabalho, tomando como pano de fundo as redes de imigração sul-americanas no início do século XX. Schettini contribui para uma reflexão sobre o comércio sexual e o trabalho de homens e mulheres à margem do mercado de trabalho assalariado. Nota-se como essa escolha torna inconveniente a abordagem de uma metodologia centrada no recorte nacional. De fato, esse tratamento das relações sociais e de trabalho marcadas pelo trânsito através das fronteiras precisa ir além do nacionalismo metodológico. Tal perspectiva também é insuficiente para lidar com as indeterminações morais e legais que essas experiências encerram, quando tais sujeitos eram registrados como "indesejáveis" nos portos em que transitavam.

Enrique Mases, por sua vez, estuda a questão indígena na Argentina em uma perspectiva que a conecta com o processo de construção e fortalecimento do Estado nacional no país. Mases nos mostra como a ideia de que o trabalho era o melhor instrumento de transformação do "índio bárbaro" em "civilizado" foi sendo reproduzida ao longo da primeira metade do século XX até uma ruptura significativa nesse processo, com a chegada dos governos peronistas ao poder. A partir de então, segundo o autor, as autoridades passaram a visualizar o indígena como mais um ator no mundo do trabalho e, portanto, como cidadão pleno da "Nova Argentina". Essa descontinuidade, entretanto, é marcada tanto pela inclusão do indígena no escopo da cidadania, como por sua exclusão, sob a invisibilidade trazida pela suposta igualdade entre ele e os demais trabalhadores.

A última chave temática da coletânea também traz como ponto central as relações entre trabalhadores e o Estado, entretanto, a partir de sua conexão com as leis e os direitos trabalhistas. Juan Suriano, ao estudar os trabalhadores argentinos na primeira metade do século XX, aborda um tema que tem balizado um número considerável de pesquisas sobre a relação da classe operária com o tema dos direitos e da justiça. Trata-se da construção, elaboradas por eles próprios, de uma linguagem de direitos, realizada por meio de sindicatos, da imprensa operária e de suas próprias correntes ideológicas. Fernando Teixeira, por sua vez, demonstra que tais sujeitos não somente apropriaram-se de um discurso legal como apoderaram-se das instituições oficiais e jurídicas para defender seus interesses. Ao estudar a relação entre greves, Justiça do Trabalho e movimento operário no período que antecedeu o golpe civil-militar no Brasil, o autor traz uma importante contribuição para a historiografia. Ele desenvolve a hipótese de que a inserção dos trabalhadores no arcabouço institucional criado desde os anos 1930, para intermediar as relações de trabalho, está no cerne do próprio golpe.

De maneira geral, a coletânea Histórias cruzadas relativiza e desafia paradigmas por muito tempo legitimados, identificados com as periodizações tradicionais, com o nacionalismo metodológico, com a noção limitada sobre o 
conceito de trabalho e de mundos do trabalho, e com as separações duvidosas entre marcadores socioculturais e eixos temáticos. Trata-se de uma versão revisitada e atualizada das transformações no campo da história social do trabalho - sob a perspectiva thompsoniana acerca da experiência social de homens e mulheres. Com efeito, o volume destaca-se pela utilização rigorosa de um copioso conjunto documental - alargamento das possibilidades empíricas que vem desde pelo menos as últimas décadas do século passado - e pelo uso de uma abordagem interseccional renovadora.

Por fim, a compilação é fruto de um diálogo muito bem-sucedido entre intelectuais de países latino-americanos. Nesse caminho, ela abre portas para outras interlocuções que sejam capazes de produzir resultados mais instigantes do que aqueles que, porventura, existiriam se estivessem sempre pautados nos ambientes historiográficos nacionais.

Recebido em 18/7/2019 Aprovado em 18/7/2019 